\title{
EVALUATE THE ANTIFERTILITY POTENTIAL OF FICUS RACEMOSA LINN BARK ON FEMALE WISTAR RATS
}

\author{
SUNIL KUMAR SHAH ${ }^{*}$, DEENANATH JHADE ${ }^{2}$, RAJENDRA CHOUKSEY ${ }^{3}$
}

${ }^{1}$ Department of Pharmaceutics, College of Pharmacy, Sri Satya Sai University of Technology and Medical Sciences, Sehore, Madhya Pradesh, India. ${ }^{2}$ Department of Pharmacognosy, College of Pharmacy, Sri Satya Sai University of Technology and Medical Sciences, Sehore, Madhya Pradesh, India. ${ }^{3}$ Department of Pharmaceutics, School of Pharmacy, Sri Satya Sai University of Technology and Medical Sciences, Sehore, Madhya Pradesh, India. Email: sunilph86@gmail.com

Received: 05 August 2016, Revised and Accepted: 15 August 2016

\section{ABSTRACT}

Objective: The present study was formulated to evaluate the antifertility potential of Ficus racemosa Linn bark on female Wistar rats.

Methods: Effects of $F$. racemosa bark extract were studied on physicochemical parameters, successive solvent extraction, and phytochemical screening and antifertility activity. After acute oral toxicity study, antifertility activity in proven fertile female Wistar rats at the doses 500 mg/kg b.wt./day for 30 days. Effects on dimensions of the reproductive outcome, anti-implantation, abortifacient, estrogenic, and antiestrogenic activity were observed.

Results: Phytochemical studies of F. racemosa bark shown a positive test for alkaloids, steroid, flavonoids, terpene, carbohydrates, and tannin. The extract of $F$. racemosa has the antifertility effect; the control rats showed a good number of litters. Treatment of animal with different extracts resulted a significant $(\mathrm{p}<0.05, \mathrm{p}<0.01)$. Antifertility activity of $56.5 \%$ and $40.3 \%$ was exhibited by alcoholic $F$. racemosa extract (AFR) and aqueous $F$. racemosa Extract (WFR), respectively. After 21 days of the extract-free period, the antifertility effect of the extracts was reversed. The extract treatment with AFR, an increase in the percentage of resorption index indicates the failure in development of embryo. The mean percentage of anti-implantation and percent resorption (abortifacient) was found to be highest for AFR-41.21\%, WFR 28.07, and AFR-32.56\%, WFR-20.76\%, respectively. The decrement in implantation caused by the extracts may be due to estrogenic or antiestrogenic activity. However, along with standard, AFR exhibiting more potent estrogenic and less potent antiestrogenic when compared with standard.

Conclusion: The above results revealed the potential, reversible female antifertility effect of alcoholic extract F. racemosa bark.

Keywords: Ficus racemosa, Antifertility, Reproductive outcome, Anti-implantation, Abortifacient study, Estrogenic and antiestrogenic activity.

(C) 2016 The Authors. Published by Innovare Academic Sciences Pvt Ltd. This is an open access article under the CC BY license (http://creativecommons. org/licenses/by/4. 0/) DOI: http://dx.doi.org/10.22159/ajpcr.2016.v9i6.14517

\section{INTRODUCTION}

This century search for antifertility agents is continued to tackle the problem of the population explosion that may lead too economic and health impact on the family in particular and the society in general, especially in developing countries like Ethiopia where the population growth is very high (Ministry of Health, 2003). Fertility control is an issue of global and national public health concern. There is a global need to support individuals in family planning due to the increasing growth rate of the world's population with its negative impact on the environment, economic growth, and poverty reduction in underdeveloped countries. About $90 \%$ of the world's contraceptive users are women. Although considerable progress has been made in the development of highly effective, acceptable, and reversible methods of contraception in females, progress and possibilities on males are still slow and limited ${ }^{1}$. Aware of this responsibility, health organizations and pharmaceutical companies continue to financially support or actively pursue research toward new contraceptive approaches [1]. Current methods of contraception result in an unacceptable rate of unintended pregnancies and many side effects also.

Ficus racemosa Linn, Family: Moraceae (commonly known in all over India as udumbara, gular), is a perennial herb that is grown in most part of India and is used in the traditional system of Indian medicine against have been recommended for the treatment of diarrhea, diabetes, hypertension, gastric ulcer, wound healing, etc. Bark of $F$. racemosa showed a wide range of pharmacological actions hypoglycemic, hyperlipidemia, renal anticarcinogenic, antidiuretic, antitussive, hepatoprotective, radioprotective, antiulcer, anti-inflammatory, antidiarrheal and antifungal, $\beta$-sitosterol, glauanol acetate, the active constituent [2]. However, scientific study of this plant in relation with the potentiality as an effective antifertility agent is still fragmentary.
The present study was, therefore, carried out to evaluate the claimed antifertility effect of $F$. racemosa bark using different aspects of reproductive physiology in Wistar rats.

\section{METHODS}

\section{Collection of plant material}

The plant specimens for the study were collected from the Satpura region of Madhya Pradesh, India, identified and authenticated by the National Institute of Science Communication and Information Resources (NISCAIR), New Delhi, a voucher specimen no. is (NISCAIR/ RHMD/Consult/2015/2859/52-1). Care was taken to select healthy fully grown plant and normal parts. The samples of different parts were cut suitably and removed from the plant and thoroughly washed with water to remove the adherent impurities and dried in sunlight [3].

\section{Determination of physicochemical parameters}

Physicochemical parameters of $\mathrm{F}$. racemosa bark were determined and reported as total ash, water-soluble ash, and acid-insoluble ash (Jarald, Edwin, 2010). Alcohol- and water-soluble extractive values were determined to find out the amount of water- and alcohol-soluble components [4]. The moisture content and $\mathrm{pH}$ were also determined (Jarald, Edwin, 2010).

\section{Successive solvent extraction}

The method is based on the extraction of active constituents present in the drug, using various solvents ranging from non-polar to polar The solvents used were petroleum ether, ethanol, and aqueous. Crude drug was subjected to Soxhlet extraction with 1.5 litters of each solvent depending on their polarity. Each time before extraction with next solvents the Marc was air-dried [5]. All the extracts were concentrated 
by distilling the solvent at low temperature. They were then weighed, and percentages of different extractive values were calculated with respect to air-dried substance.

\section{Phytochemical screening}

Identification of the chemical constituents was carried out on the powdered bark of $F$. racemosa, and the extract was concentrated and subjected to various chemical tests to detect the presence of different phytoconstituents [6].

\section{Acute oral toxicity}

The acute oral toxicity studies were carried out as per the guidelines of Organization for Economic Co-operation and Development-423, Ministry of Social Justice and Empowerment, Government of India.

\section{Animals}

Antifertility test was performed on adult female Wistar rats weighing between 180 and $200 \mathrm{~g}$ and mice. They were housed in polypropylene cages and fed with standard chow diet and water ad labium. The Institutional Ethical Committee for animal cares and use approved all experimental procedures. The animals were exposed to alternate cycle of $12 \mathrm{hrs}$ of darkness and light each. Before each test, the animals were fasted for at least $12 \mathrm{hrs}$. The experimental protocols were subjected to the securitization of the Institutional Animal Ethics Committee and were cleared by the same $(1587 / \mathrm{PO} / \mathrm{Re} / \mathrm{S} / 11 / \mathrm{CPCSEA})$.

\section{Antifertility activity}

Antifertility activity of plant extracts was evaluated with the help of reproductive outcome, anti-implantation, abortifacient, estrogenic, and antiestrogenic study was also performed, which further supported by the hormonal analysis [7-9].

\section{Reproductive outcome study}

Three groups of mature female rates (five rat/group) were selected for received extracts for 8 days, and control group received vehicle for the same period. All the experimental rats were then allowed to mate with mature fertile male rat and the treatment continued for 21 days. The number of litters was determined after the completion of one gestation period in all-experimental groups. The litters were allowed to grow and the growth of litters produced from the extract-administered group was compared with those of control group. The reversibility of antifertility effect of the extracts was also studied in the treated groups. For this study, the extracts were administered continuously for 21 days, and then, the extract was withdrawn. After 21 days of extracts withdrawal, animals were allowed to mate with male rate. The number of litters was determined after the completion of one gestation period (Salhad et al., 1997).

\section{Anti-implantation study}

With the help of estrous cycle studies, proven fertile female Wistar rats, weighing between 150 and $200 \mathrm{~g}$, were selected and left overnight with male of proven fertile in the ratio of 3:1 (Jain et al. 2012). The extracts were administered orally to separated group rats at the dose level of $500 \mathrm{mg} / \mathrm{kg}$ from day 1 to day 7 of pregnancy. Control animal received the vehicle (carboxymethyl cellulose [CMC] $0.5 \%$ ). The animals were then laparotomized on day 10 of the pregnancy under excess dose of thiopentone sodium and uteri were examined to determine the number of implantation sites (Salhad et al., 1997).

\section{Abortifacient study}

Female rats at $1^{\text {st }}$ day of pregnancy were divided into three groups, consisting of (5-6) animals in each group. The animals were laparotomized under light ether anesthesia and semi-sterile conditions on $10^{\text {th }}$ day of pregnancy. Both horns of the uterus were observed for the number of implants. The rats were sutured and allowed to recover. The first group served as control and received vehicle only (Tween-80, $1 \%$ ) and group second and third received suspension of extract at a dose of $500 \mathrm{mg} / \mathrm{kg} \mathrm{b}$. wt. in $1 \%$ Tween-80, respectively, from day 10 to 18 of pregnancy. During the experiment, animals were observed for vaginal bleeding. On $21^{\text {st }}$ day, animals were laparotomized under light ether anesthesia and observed for number of litters and percentage of resorption compared with the initial number of implantation observed on $10^{\text {th }}$ day of pregnancy (Khanna and Chaudhury, 1968).

\section{Estrogenic and antiestrogenic study}

Colony breed immature ovariectomized female rats (21-23 days) weighing between 25 and $30 \mathrm{~g}$ were used. They were divided into experimental and control groups, consisting of six animals each group. The extracts were suspended in $0.5 \%$ CMC and administered orally for 7 days at the dose level of $500 \mathrm{mg} / \mathrm{kg}$ body weight. Ethinyl estradiol (Unicure Remedies Pvt. Ltd., Baroda, India) in olive oil $1 \mu \mathrm{g} / \mathrm{rat} /$ day was injected subcutaneously for 7 days in another group to induce estrous. CMC $0.5 \%$ was administered orally to the control animals. The extract at the dose level of $500 \mathrm{mg} / \mathrm{kg}$ was also administered orally along with ethinyl estradiol in olive oil at $1 \mu \mathrm{g} / \mathrm{rat} /$ day subcutaneously to different groups of rat for the same period (Sharma, 2003).

On the $8^{\text {th }}$ day of the experiment, all the animals were sacrificed by decapitation under light ether anesthesia, and the uteri were dissected out, surrounding tissues removed, blotted on filter paper, and weighed quickly on balance sensitive to $0.0001 \mathrm{~g}$. A portion of the uterine tissues and adrenal glands from the control and treated animals were fixed in Bouin's fluid for $24 \mathrm{hrs}$, dehydrated in alcohol and then embedded in paraffin. The paraffin blocks were sectioned at $6 \mathrm{~mm}$ intervals and stained with hematoxylin-eosin for histological examinations (Pal, 1990).

\section{Hormonal analysis}

Hormonal analysis was determined by Merck Kit method (Merck cat\# 15891) using microlab-300 IX Merck apparatus (Autoanalyzer). Blood $(2 \mathrm{ml})$ was drawn by retro-orbital puncture and was immediately transferred into ethylenediaminetetraacetic acid coated vacationer. The samples were mixed gently and were left for more than half an hour at room temperature, and finally centrifuged at $3000 \mathrm{rpm}$ for 15 minutes. Serum was separated and assayed for follicle-stimulating hormone (FSH), luteinizing hormone (LH), 17 $\beta$-estradiol, prolactin, and 17-OH progesterone using enzyme-linked immunoassay technique (Elisa reader [BIORAD 680 Microplate Reader]) $[10,11]$.

\section{Statistical data}

All values are expressed as mean \pm standard error of the mean. Means were statistically analyzed by one-way analysis of variance, and values of $\mathrm{p}<0.05$ were considered statistically significant.

\section{RESULTS AND DISCUSSION}

\section{Physicochemical parameters}

Physicochemical parameters of $F$. racemosa bark were determined. In physicochemical parameter, total ash is approximately seven times and four times more than acid-insoluble ash and water-soluble ash, respectively. Ethanol soluble extractive is approximately two times higher than water-soluble extractive. Moisture content was $<7.6 \%$ and pH was 6.8 were shown in Table 1

\section{Preliminary phytochemical investigation}

A number of phytoconstituents from natural sources have been proved efficacy to prevent the pregnancy. Many scientific reports were published for the antifertility activity of flavonoids (Hiremath

Table 1: Various physicochemical parameters

\begin{tabular}{ll}
\hline Physicochemical parameter & Value $\% \mathbf{w} / \mathbf{w}^{*}$ mean \pm SD \\
\hline Total ash & $14.5 \pm 0.5$ \\
Acid-insoluble ash & $1.90 \pm 0.1$ \\
Water-soluble ash & $3.75 \pm 0.2$ \\
Water-soluble extract & $3.75 \pm 0.3$ \\
Ethyl alcohol-soluble extract & $7.0 \pm 0.3$ \\
Moisture content & 7.6 \\
pH & 6.8 \\
\hline
\end{tabular}

w/w*: Weight/weight. Value (\%) mean \pm SD. SD: Standard deviation 
et al., 2000), glycosides, alkaloids, and steroid (Sadik et al., 2001). Phytochemical investigation of $F$ racemosa, alkaloid, glycoside, tannin, and steroid were present in the alcoholic extract (Table 2). Whereas, glycoside, steroid, and tannin were present in petroleum ether extract and terpene, flavonoids, glycoside, and tannins were present in the aqueous extract (WE). The successive solvent extraction with petroleum ether, alcohol, and aqueous water gave $2.5 \%, 5.8 \%$, and $4.0 \%$, respectively, practical yield.

\section{Acute oral toxicity}

Acute toxicity studies were carried out to evaluate toxicity and to determine the minimum lethal dose of the drug extracts, using Wistar rats. No clinical signs were evident in any animal during the treatment period (clinical observations include changes in skin and fur, eyes and mucous membranes, and also respiratory, circulatory, autonomic and central nervous systems, and somatomotor activity and behavior pattern, tremors, convulsions, salivation, diarrhea, lethargy, sleep and coma). No mortality as well as any clinical sign of toxicity has been observed at a dose level of $2000 \mathrm{mg} / \mathrm{kg}$ indicating that all the extracts come under category 5, and hence, LD50 cut-off was found to be $2000 \mathrm{mg} / \mathrm{kg}$ body weight. Hence, one-five of this dose, i.e., up to $500 \mathrm{mg} / \mathrm{kg}$ body weight, was used for antifertility investigation. Hematological and biochemical parameters were also performed before and after treatment and no significant changes were observed [12-16].

\section{Reproductive outcome study}

Table 3 shows the effect of different extracts on the fertility of female rats. The control rats showed good number of litters. Treatment of animal with different extracts resulted a significant $(\mathrm{p}<0.05, \mathrm{p}<0.01)$ A significant antifertility activity of $56.5 \%$ and $40.3 \%$ was exhibited by alcoholic $F$. racemosa extract (AFR) and aqueous $F$. racemosa extract (WFR), respectively.

It was also found that the litters of the extract treated rats did not show any physical deformity. All litters grew up to the normal adult stage, which indicates that the extracts do not have a teratogenic effect, and

Table 2: Preliminary phytochemical study of Ficus racemosa bark

\begin{tabular}{llll}
\hline \multirow{2}{*}{ Test for constituent } & \multicolumn{2}{l}{ F racemosa bark } & \\
\cline { 2 - 4 } & PEE & AE & WE \\
\hline Alkaloid & $-\mathrm{ve}$ & $+\mathrm{ve}$ & $-\mathrm{ve}$ \\
Steroid & $+\mathrm{ve}$ & $+\mathrm{ve}$ & $-\mathrm{ve}$ \\
Terpene & $-\mathrm{ve}$ & $+\mathrm{ve}$ & $+\mathrm{ve}$ \\
Flavonoid & $-\mathrm{ve}$ & $+\mathrm{ve}$ & $+\mathrm{ve}$ \\
Glycoside & $+\mathrm{ve}$ & $+\mathrm{ve}$ & $+\mathrm{ve}$ \\
Sugars & $-\mathrm{ve}$ & $+\mathrm{ve}$ & $+\mathrm{ve}$ \\
Saponins & $-\mathrm{ve}$ & $-\mathrm{ve}$ & $-\mathrm{ve}$ \\
Tannin & $+\mathrm{ve}$ & $+\mathrm{ve}$ & $+\mathrm{ve}$ \\
Carbohydrate & $+\mathrm{ve}$ & $+\mathrm{ve}$ & $+\mathrm{ve}$ \\
Color and & Greyish-green & Brown & Dark brown \\
consistency & colour & & \\
Yield & 2.5 & 5.8 & 4.0 \\
Code & PFR & AFR & WFR \\
\hline
\end{tabular}

Whereas code PFR: Petroleum ether Ficus racemosa extract, AFR: Alcoholic Ficus racemosa extract and WFR: Aqueous Ficus racemosa extract. PEE: Petroleum ether extract, AE: Alcoholic extract, WE: Aqueous extract

Table 3: Effect of extracts on reproductive outcome

\begin{tabular}{llll}
\hline Group & Estrous cycle & Fertility (\%) & Litters present \\
\hline Control & Regular & $100+\mathrm{ve}$ & $10.00 \pm 0.03$ \\
AFR & Irregular & $56.5-\mathrm{ve}$ & $4.35 \pm 0.05^{\mathrm{a}}$ \\
WFR & Irregular & $40.3-\mathrm{ve}$ & $5.90 \pm 0.02^{\mathrm{a}}$ \\
W.D-AFR & Regular & $91+\mathrm{ve}$ & $9.10 \pm 0.10^{\mathrm{a}}$ \\
W.D-WFR & Regular & $90.2+\mathrm{ve}$ & $9.02 \pm 0.10^{\mathrm{b}}$
\end{tabular}

Whereas WD-AFR: Withdrawal alcoholic Ficus racemosa extract and WD-WFR: Withdrawal aqueous Ficus racemosa extract. Values are expressed as mean \pm SD. $p$ values $a=p<0.05, b=p<0.01$, when compared with normal control the absence of teratogenic effect of extracts at a given dose justifies the safety of the plant. The present observations agree with Salhad et al., (1997), who reported the reversible antifertility effect of Ricinus communis (castor beans) on female rabbits and also supported by Endalk et al., (2005), who reported the same effect of the methanolic root extract of Rumex steudelii on female rats.

After 21 days of the extract-free period, the antifertility effect of the extracts was reversed for all animals. An increase in the number of litters observed in all the post-treatment groups may indicate the reversible antifertility effect of all extracts. These observations correlate the findings of Ganguly et al. (2007) and Gebrie et al. (2005), who reported the reversible antifertility effect with similar observations on the treatment with methanolic extract of Cissampelos pareira leaves in mice and methanolic root extract of $R$. steudelii in rats, respectively. The animal groups gave $9.06 \pm 0.15$ litters at an average. This showed that there was no statistically significant change from the control group $(10.00 \pm 0.03)$.

\section{Anti-implantation and abortifacient activities}

Postcoital antifertility study showed the anti-implantation activity in the treated animals. Treated animals delivered litters, which was significantly less than control (Table 4). The extract treatments with AFR, significantly $(\mathrm{p}<0.001)$ reduced the number of litters born (Table 5). This indicates the abortifacient nature of extracts. An increase in the resorption index (\%) by the extract is an indication of failure in the development of the embryo (Dhanwad et al., 2005). Such occurrence of fetal resorption suggests that interruption of pregnancy also occurred after implantation (Elbetieha, 2000). These observations indicate the pregnancy terminating potential of the extract. Embryonal resorption could be due to modifications of uterine lining function or maternal toxicity which consequently may increase early resorption and late fetal death (Chaves, 1985; Khera, 1987). Hence, the present investigation clearly reveals that the extracts are effective before and after the implantation occurs (Vasudeva and Sharma, 2006).

Both these activities were calculated on the basis of number of implants and number of litters. The mean percentage of anti-implantation and percent resorption (abortifacient) were found to be highest for AFR-41.21\% and WFR 28.07, whereas in the case of percent resorption AFR-32.56\% and WFR-20.76\%. These results (Tables 4 and 6) indicated that all the extracts inhibited the conversion or development of implants into litters. The decrement in implantation caused by the extracts may be due to estrogenic or antiestrogenic activity as described by Hafez (1970).

\section{Estrogenic and antiestrogenic study}

Antifertility activity of all the extracts was finally evaluated with the help of estrogenic and antiestrogenic activity associated with hormonal level and histological parameters such as uterine weight, diameter of uterus, thickness of endometrium, and height of endometrium epithelium. The stages of estrous cycle and its duration were determined as described by Makonnen et al. (1997). The detailed data have given in Tables 7 and 8. The uterotropic potency, in terms of the weight of uterus, AFR was found to be $84.23 \%$, and WFR was found to be $59.11 \%$ when compared with standard (ethinyl estradiol). The number of cornified cells in vaginal smears was considerably higher $(+$ to ++$)$ than that of controls $(0$ to +$)$ but notably less than that of ethinyl estradiol-treated rats $(+++)$. All the treated rats showed open vagina. Oral administration of alone AFR and WFR at a dose level $500 \mathrm{mg} / \mathrm{kg}$ body weight, AFR shows highly significant $(\mathrm{p}<0.001)$ change in uterine weight, thickness of endometrial epithelium, and height of endometrial epithelium while WFR shows less significant $(\mathrm{p}<0.001)$ as compared with that of control.

However, along with standard, AFR exhibiting strong estrogenic property, increase in uterine weight, diameter of uterus, thickness of endometrium, and height of endometrial epithelium and WFR exhibiting strong antiestrogenic property, decrease in uterine weight, diameter of uterus, thickness of endometrium, and height of endometrial epithelium 
Table 4: Effect of extracts on anti-implantation activity

\begin{tabular}{llll}
\hline Treatment (dose) & \multicolumn{2}{l}{ Anti-implantation activity } & \\
\cline { 2 - 4 } & Number of implants & Number of litters & Mean \% anti-implantation \\
\hline Control & $7.23 \pm 0.52$ & $7.20 \pm 0.65$ & Nil \\
AFR & $4.25 \pm 0.68$ & $4.20 \pm 0.05$ & $41.21^{\mathrm{a}}$ \\
WFR & $5.20 \pm 0.29$ & $5.10 \pm 0.42$ & $28.07^{\mathrm{b}}$ \\
\hline
\end{tabular}

Values are expressed as mean \pm SD. $p$ values $a=p<0.05, b=p<0.01$

Table 5: Hormonal levels in various groups of animals

\begin{tabular}{|c|c|c|c|c|c|}
\hline Treatment $500 \mathrm{mg} / \mathrm{kg}$ & LH & FSH & Prolactin & $17 \beta$ estradiol & 17-0H progesterone \\
\hline Control & $6.25 \pm 2.42$ & $8.64 \pm 5.20$ & $40.25 \pm 6.10$ & $745.12 \pm 45.40$ & $14.54 \pm 1.10$ \\
\hline AFR & $6.05 \pm 2.70^{\mathrm{a}}$ & $7.98 \pm 5.20$ & $43.12 \pm 4.11$ & $730 \pm 10.12$ & $30.16 \pm 1.12$ \\
\hline WFR & $4.92 \pm 1.40^{\mathrm{a}}$ & $4.58 \pm 6.20$ & $32.42 \pm 7.10$ & $535 \pm 01.10$ & $28.24 \pm 2.24$ \\
\hline
\end{tabular}

$\mathrm{n}=5$, data representation as mean \pm SD. $\mathrm{p}$ values $\mathrm{a}=\mathrm{p}<0.05, \mathrm{~b}=\mathrm{p}<0.01, \mathrm{c}=\mathrm{p}<0.001$ when compared with normal control. LH: Luteinizing hormone, FSH: Follicle-stimulating hormone

Table 6: Effect of extracts on abortifacient activity

\begin{tabular}{llll}
\hline \multirow{2}{*}{ Treatment (dose) } & Abortifacient activity & \\
\cline { 2 - 4 } & Number of implants & Number of litters & Resorption \% \\
\hline Control & $7.32 \pm 0.62$ & $7.10 \pm 0.30$ & 3.00 \\
AFR & $4.98 \pm 0.53$ & $4.95 \pm 0.55$ & $32.56^{\mathrm{a}}$ \\
WFR & $6.10 \pm 0.10$ & $5.80 \pm 0.45$ & $20.76^{\mathrm{a}}$ \\
\hline
\end{tabular}

Values are expressed as mean \pm SD. $p$ values $a=p<0.05, b=p<0.01$, when compared with normal control

Table 7: Effect of extracts on estrogenic and antiestrogenic study

\begin{tabular}{lll}
\hline Treatment (dose) & $\begin{array}{l}\text { Uterine weight } \mathbf{m g} / \mathbf{1 0 0} \mathbf{g} \\
\text { body weight; mean } \pm \text { SD) }\end{array}$ & Vaginal cornification \\
\hline Control & $70.24 \pm 5.35^{\mathrm{a}}$ & NIL \\
Ethinyl estradiol $(1 \mu \mathrm{g} / \mathrm{rat} /$ day) & $335.40 \pm 7.56^{\mathrm{a}}$ & +++ \\
AFR $(500 \mathrm{mg} / \mathrm{kg})$ & $278.83 \pm 5.82^{\mathrm{a}}$ & + to ++ \\
WFR $(500 \mathrm{mg} / \mathrm{kg})$ & $198.05 \pm 5.25^{\mathrm{a}}$ & ++ \\
Ethinyl estradiol $(1 \mu \mathrm{g} / \mathrm{rat} /$ day)+AFR $(500 \mathrm{mg} / \mathrm{kg})$ & $425.23 \pm 05.48^{\mathrm{a}}$ & ++ \\
Ethinyl estradiol $(1 \mu \mathrm{g} / \mathrm{rat} /$ day)+WFR $(500 \mathrm{mg} / \mathrm{kg})$ & $325.12 \pm 04.25^{\mathrm{b}}$ & ++ \\
\hline
\end{tabular}

Values are expressed as mean \pm SD. $p$ values $a=p<0.05, b=p<0.01, c=p<0.001$ when compared with normal control. Whereas +: Nucleated epithelial cells, ++: Nucleated epithelial cells and cornified cells, +++: Cornified cells

Table 8: Histological changes in the uterus and endometrium after treatment with extracts

\begin{tabular}{|c|c|c|c|}
\hline Treatment (Dose) & $\begin{array}{l}\text { Diameter of } \\
\text { uterus }(\mu \mathrm{m} \pm \mathrm{SD})\end{array}$ & $\begin{array}{l}\text { Thickness of endometrium } \\
(\mu \mathrm{m} \pm \mathrm{SD})\end{array}$ & $\begin{array}{l}\text { Height of endometrial } \\
\text { epithelium }(\mu \mathrm{m} \pm \mathrm{SD})\end{array}$ \\
\hline Control & $330.54 \pm 5.25^{\mathrm{a}}$ & $54.14 \pm 2.12$ & $17.4 \pm 0.25^{\mathrm{a}}$ \\
\hline Ethinyl estradiol ( 1 $\mu \mathrm{g} / \mathrm{rat} /$ day $)$ & $821.25 \pm 6.25^{\mathrm{a}}$ & $245.45 \pm 15.15^{\mathrm{a}}$ & $45.10 \pm 4.18^{\mathrm{a}}$ \\
\hline $\operatorname{AFR}(500 \mathrm{mg} / \mathrm{kg})$ & $645.05 \pm 4.62^{c}$ & $274.15 \pm 65.42^{c}$ & $72.40 \pm 4.10^{c}$ \\
\hline WFR $(500 \mathrm{mg} / \mathrm{kg})$ & $327.14 \pm 2.14^{b}$ & $195.05 \pm 2.05^{\mathrm{b}}$ & $45.40 \pm 2.44^{\mathrm{b}}$ \\
\hline Ethinyl estradiol $(1 \mu \mathrm{g} / \mathrm{rat} /$ day $)+\mathrm{AFR}(500 \mathrm{mg} / \mathrm{kg})$ & $945.45 \pm 4.62^{\mathrm{a}}$ & $274.15 \pm 65.42^{\mathrm{a}}$ & $72.40 \pm 4.10^{\mathrm{a}}$ \\
\hline Ethinyl estradiol $(1 \mu \mathrm{g} / \mathrm{rat} /$ day $)+W F R(500 \mathrm{mg} / \mathrm{kg})$ & $524.48 \pm 2.02^{\mathrm{a}}$ & $162.15 \pm 7.12^{\mathrm{a}}$ & $34.14 \pm 4.25^{\mathrm{a}}$ \\
\hline
\end{tabular}

Values are expressed as mean \pm SD. $p$ values $a=p<0.05, b=p<0.01, c=p<0.001$ when compared with normal control

when compared with standard. These observations are similar to the finding of Ravichandran et al. (2007) and Vishnukant and Rana (2010) on the effect of hydroalcoholic extract of ailanthus excels (Roxb.) stem bark and Plumbago zeylanica leaves on the uterus of female Wistar rats. These observations revealed that these extracts acted as a competitive antagonist to ethinyl estradiol. Hence, the anti-implantation activity of these extract may be due to their antiestrogenic nature, which antagonise the action of estrogen and cause structural and functional changes in the uterus and finally decreases the implantation [17-21].

\section{Hormonal analysis}

Sex hormones were assayed based on their roles in maintaining pregnancy since a failing pregnancy could be correlated to the levels of these hormones in the body fluids (Yakubu and Bukoye, 2009). The reduction in the concentration of FSH is an indication of disturbance of estrus cycle and ovulation (Ganguly et al., 2007). LH is required for continued development and normal function of corpora lutea. The significant reduction in the level of serum LH could be associated with the physiological process of luteolysis preceding parturition (Yakubu and Bukoye, 2009). It could be attributed to pregnancy failure resulting from a luteal phase that is not being maintained. The reduced level of hormone may also be due to inactivation of luteinization of ovarian follicles, which could be responsible for the reduction in the concentration of serum progesterone in this study [14,22-28]. An elevated level of progesterone during pregnancy plays a key role in maintaining the conditions and is an 
important factor in the implantation process. Therefore, luteolysis and reduction in the blood levels of progesterone may contribute to abortion and anti-implantation activity of all extracts $[29,30]$. The findings of the present study were agreed with previous studies which reported the effect of Inula viscose and Bambusa vulgaris leaf extract on implantation and abortion in rats and rabbits (Yakubu and Bukoye, 2009). In this study, an increase in prolactin level was observed (Table 5); these findings were also supported by Ganguly et al. (2007), who reported that a combination of enhanced prolactin and suppressed LH secretion is due to prolongation of estrus cycle (Ganguly et al., 2007). An imbalance in endogenous estrogen and progesterone levels could be responsible for anti-implantation activity (Dhanwad et al., 2005)

\section{CONCLUSION}

The present findings inferred that the gathering treated with the most noteworthy convergence of plant concentrate indicated great come about as that of the standard medication and was underpinned by histopathological investigations of the antifertility activity on female Wistar rats. Antifertility activity of plant extracts was evaluated with the help of reproductive outcome, anti-implantation, abortifacient, estrogenic, and antiestrogenic study was also performed, which further supported by the hormonal analysis. It is well known that for implantation exact equilibrium of estrogen and progesterone is essential and any disturbance in the level of these hormones may cause infertility. In our study, it clearly demonstrates that extract of $F$. racemosa bark, the control rats showed good number of litters. Treatment of animal with different extracts resulted a significant $(\mathrm{p}<0.05, \mathrm{p}<0.01)$. A significant antifertility activity (56.6\%) was exhibited by AFR. It was also found that the litters of the extract treated rats did not show any physical deformity. All litters grew up to the normal adult stage, which indicates that the extracts do not have a teratogenic effect, and the absence of teratogenic effect of extracts at a given dose justifies the safety of the plant. After 21 days of the extract-free period, the antifertility effect of the extracts was reversed for all animals. An increase in the number of litters observed in all the post-treatment groups may indicate the reversible antifertility effect of all extracts.

Estrogenic in nature at the dose of $500 \mathrm{mg} / \mathrm{kg}$ b.wt. as evident form the along with standard, AFR AE significance increases in the diameter of uterus, height of endometrial epithelium, and thickness of endometrium in extracted animal, whereas, along with standard, WFR WE $500 \mathrm{mg} / \mathrm{kg}$ b.wt. showed less antiestrogenic in nature decrease in the diameter of uterus, height of endometrial epithelium, and thickness of endometrium in extracted animal. It is a suitable plant for developing antifertility drug F. racemosa is recommended for working out and should be experimented for the antifertility program. Further studies on mechanism of antifertility action and isolation of the active components responsible for antifertility effect are in progress.

\section{REFERENCES}

1. Kirtikar KR, Basu BD., Indian Medicinal Plants. Vol. III. $2^{\text {nd }}$ ed. Dehradun: International Book Distributors; 2005.

2. Ganguly M, Kr Borthakur M, Devi N, Mahanta R. Antifertility activity of the methanolic leaf extract of Cissampelos pareira in female albino mice. J Ethnopharmacol 2007;111(3):688-91.

3. Council of Scientific and Industrial Research. Wealth of India Raw materials. New Delhi (India): Council of Scientific and Industrial Research; 1956. p. 4.

4. The Wealth of India. A Dictionary of Indian Raw Materials and Industrial Products. Vol. 4. New Delhi: Council of Scientific and
Industrial Research; 1999. p. 246.

5. Gupta S. Sampling and test of significance. In Gupta S, editor Statistical Methods. New Delhi: Sultan Chand and Sons Publishers; 1978. p. 58-76.

6. Chopra RN, Chopra IC, Varma BS. Supplement to Glossary of Indian Medicinal Plants. Reprinted edition. New Delhi: CSIR; 1992. p. 29.

7. Anonymous. The Wealth of India, Raw Materials. Vol. 4. New Delhi Council of Scientific and Industrial Research; 1952. p. 35-6.

8. Anonymous. Pharmacopoeia of India. Vol. 2. Government of India, Delhi: Manager of Publication, Ministry of Health; 1966. p. 947-8.

9. Farnsworth NR. Biological and phytochemical screening of plants J Pharm Sci 1966;55(3):225-76.

10. Harborne JB. Phytochemical methods. A Guide to Modern Techniques of Plant Analysis. $2^{\text {nd }}$ ed. London: Chapmann and Hall; 1984. p. 192.

11. Warrier PK. Indian Medicinal Plants, A Compendium of 500 Species. Vol. 3. Chennai: Orient long man Ltd.; 1996. p. 34-s5.

12. Kokate CK., Practical Pharmacognosy. New Delhi: Vallabh Prakashan; 1999. p. 107-8.

13. Khan N, Sultana S. Modulatory effect of Ficus racemosa: Diminution of potassium bromate-induced renal oxidative injury and cell proliferation response. Basic Clin Pharmacol Toxicol, 2005;97(5):282-8.

14. Sandeep G, Dheeraj A, Sharma NK, Jhade D, Bharti A. Effect of plumbagin free alcohol extract of Plumbago zeylanica Linn. root on reproductive system of female Wistar rats. Asian Pac J Trop Med 2011;4(12):978-84.

15. Ahmed F, Urooj A. Hepatoprotective effects of Ficus racemosa stem bark against carbon tetrachloride-induced hepatic damage in albino rats. Pharm Biol 2010;48(2):210-6.

16. Rithaporn T, Monga M, Rajasekaran M. Curcumin: A potential vaginal contraceptive. Contraception 2003;68(3):219-23

17. Bhaskara Rao R, Murugesan T, Pal M, Saha BP, Mandal SC. Antitussive potential of methanol extract of stem bark of Ficus racemosa Linn. Phytother Res 2003;17(9):1117-8.

18. Chandrashekhar $\mathrm{CH}$., Anthelmintic activity of the crude extracts of Ficus racemose, Int J Green Pharm 2008;5(5):100-3.

19. Wikhe M, Zade V, Dabhadkar D, Pare S. antifertility effect of alcoholic and aqueous extracts of Dolichandrone Falcata leaves on estrous cycle of female albino rats, Int J Pharm Pharm Sci 2012;4(3):462-5.

20. Hoyer PB. Damage to ovarian development and function. Cell Tissue Res 2005;322(1):99-106.

21. Wassarman PM, Albertini, DF. Cellular and molecular biology of the mammalian ovum. In: Knobil E, Neill JD, editors. The Physiology of Reproduction. $2^{\text {nd }}$ ed., Vol. 1. New York: Raven Press; 1994. p. 79-122.

22. Mishra V, Khan NU, Singhal KC. Potential antifilarial activity of fruit extracts of Ficus racemosa Linn. against Setaria cervi in vitro. Indian J Exp Biol 2005;43(4):346-50.

23. Dhanwad R, Purohit MG, Patil SB, Satyanarayan ND. Anti-implantation activity of ethanolic extract of Cardiospermum halicacabum L. (Sapindaceae) in albino rats. Indian Drugs 2005;42(11):726-30.

24. Singh K, Gupta RS. Antifertility activity of $\beta$-sitosterol isolated from Barleria prionitis (L.) roots in male albino rats. Int J Pharm Pharm Sci 2016;8(5):88-96.

25. Pradeepa M, Kalidas V, Geetha N. Qualitative and quantitative panalysis and bactericidal activity of Pelargonium graveolens L'HER. Int J App Pharm 2016;8(3):7-11.

26. Chauhan A, Agarwal M, Kushwaha S, Mutreja A. Antifertility studies of Aegle marmelos Corr., an Indian medicinal plant on male albino rats. Egypt J Biol 2008; 10:28-35

27. Vasudeva N, Sharma SK. Post-coital antifertility activity of Achyranthes aspera Linn. root. J Ethnopharmacol 2006;107(2):179-81.

28. Okoko II, Osinubi AA, Olabiyi OO, Kusemiju TO, Noronha CC, Okanlawon AO. Antiovulatory and anti-implantation potential of the methanolic extract of seeds of Abrus precatorius in the rat. Endocr Pract 2010;16(4):554-60.

29. Madhavan V, Kumar BH, Murali A, Yoganarasimhan SN. Antifertility activity of Drosera burmannii. Pharm Biol 2009;47(2):128-31.

30. Salhad AS, Issa AA, Alhougog I. On the contraceptive effect of castor beans. Indian J Nat Med 1997;35:63-5. 